\title{
SENTENÇAS DE MEDIDA SOCIOEDUCATIVA DE INTERNAÇÃO E GÊNERO - O OLHAR DOS MAGISTRADOS EM PERNAMBUCO SOBRE AS ADOLESCENTES EM CONFLITO COM A LEI
}

\author{
SENTENCES OF YOUTH DETENTION AND GENDER - THE LOOK OF THE \\ MAGISTRATES IN PERNAMBUCO ON FEMALE ADOLESCENTS IN CRIME
}

\author{
Érica Babini Lapa do Amaral Machado* \\ Williams França da Silva** \\ Andrielly Stephany Gutierres Silva***
}

\begin{abstract}
RESUMO
O atual contexto de elevação das taxas de medidas de internação de adolescentes do sexo feminino - sob o olhar teórico da criminologia crítica feminista subsidiada pela Teoria dos Rótulos - justifica e impõe a seguinte indagação: as percepções do magistrado referentes a gênero, tais como "o papel da mulher" e a expectativa sobre este "papel”, decorrentes da estrutura patriarcal da sociedade, influenciam na decisão de aplicação da sentença? A pesquisa, pois, objetivou investigar a existência, por parte do magistrado, de estereótipos consistentes em elementos de gênero. Para tal, foram utilizados os métodos dedutivo de análise de bibliografia que aborda a problemática de gênero no seio das relações sociais e a análise de conteúdo (AC) de vinte e oito sentenças proferidas nos anos de 2010 a 2012, no estado de Pernambuco. Identificaram-se argumentos dos magistrados referentes às concepções patriarcais, classificados em categorias, os quais subscrevem uma visão estereotipada de gênero, imbuída de um desejo camuflado de controle do feminino, de modo que a atividade judicante funciona como um mecanismo público de punição àquelas meninas que escapam ao controle informal, reforçando o controle patriarcal ao criminalizá-las em situações específicas, especialmente quando transcendem o ethos reservado ao papel feminino.
\end{abstract}

\section{PALAVRAS-CHAVE}

Adolescentes femininas. Decisões judiciais. Estereótipos. Gênero.

\begin{abstract}
Considering the current high rates of detention of female adolescents - under the theoretical view of the feminist critic criminology, subsidized by the labeling approach - the following question is justified and necessary: Do the perceptions of magistrates regarding gender - such as "the role of woman" and the expectation about this "role", fruit of the patriarchal structure of the society influence the judicial sentencing decision? The research aimed to investigate the existence, by the magistrates, of gender-stereotype elements. To this end it was used the deductive methods of analysis of bibliography that covers gender issues within social relations as well as the analysis of

\footnotetext{
* Doutora em Direito pela Universidade Federal de Pernambuco. Professora de Direito Penal e Criminologia da Universidade Católica de Pernambuco (Recife, PE, Brasil). Integrante do Grupo Asa Branca de Criminologia. E-mail: ericababini@hotmail.com

** Graduado em Filosofia pela Universidade Federal de Pernambuco. Estudante do curso de Direito da Universidade Católica de Pernambuco (Recife, PE, Brasil). Pesquisador do Grupo Asa Branca de Criminologia. E-mail: willamsfranca@yahoo.com.br

*** Estudante do curso de Direito da Universidade Católica de Pernambuco (Recife, PE, Brasil). Pesquisador do Grupo Asa Branca de Criminologia. E-mail: andrielly111@gmail.com
} 
the content of twenty-eight sentences given by magistrates from 2010 to 2012 in the state of Pernambuco (Northeast Brazil). The arguments of the magistrates were regarded as patriarchal conceptions, classified into categories which endorse a stereotypical vision of gender, imbued with a camouflaged desire of control over females, so that the judicial activity works as a public mechanism of punishment to those girls who run away from the informal control, reinforcing the patriarchal control by criminalizing them in specific situations, notably when they transcend the ethos reserved for the female role.

\section{KEYWORDS}

Female adolescents. Judicial decisions. Stereotypes. Gender.

\section{INTRODUÇÃO}

A efetividade de um olhar mais sensível e comprometido com mudanças no sentido da proteção especial a grupos marcados socialmente pela vulnerabilidade, especialmente no que se refere às crianças e aos adolescentes, deve-se, ainda que em parte e com ressalvas, à Declaração Universal dos Direitos Humanos.

O anterior assento cientificista, supostamente protetivo, mas caracterizado, paradoxalmente, pela tutela da pobreza (por meio do binarismo carência/delinquência), pela punição, pela suspensão de garantia e pela exclusão (GARCÍA MÉNDEZ, 1998), encontra, no limite de sua superação, a Convenção dos Direitos da Criança (CDC) de 1989. O documento representou a conjugação de esforços, interesses, credos e comprometimentos, sob a marca da diversidade ideológica, na busca pelo estabelecimento de uma comunidade interessada com a defesa e a concretização dos direitos humanos das crianças e dos adolescentes (COIMBRA, 2005).

Uma concepção central da Convenção é a da proteção integral, que se estabelece com força imperativa e coercitiva de âmbito internacional, obrigando os Estados a respeitar e contribuir com políticas afirmativas, em conjunto com os pais, para a realização dos direitos nela propugnados (DOLINGER, 2003).

No caminho seguido pela doutrina da proteção integral, não se pode deixar de fazer referência, no contexto da política e da legislação nacional, à Constituição Federal de 1988 (que trouxe, mesmo antes da Convenção dos Direitos da Criança, a Doutrina da Proteção Integral) e ao Estatuto da Criança e do Adolescente - ECA (Lei 8.069/90). Há, assim, um novo escopo de demarcação paradigmática: os direitos fundamentais impõem-se não só como o conjunto de normas orientadoras da intervenção estatal para a (suposta) proteção, mas também, e principalmente, como limite a essa intervenção, sobretudo nos casos em que crianças e adolescente em conflitos com a lei figuram como parte em processo. Na esteira dessa evolução, uma importante inversão: o juiz, figura central e decisiva dos rumos do processo, cede lugar ao império do sistema legal garantista. 
Porém, mesmo diante dessa quase "revolução copernicana”, urge perguntar: houve, de fato, uma evolução no trato - efetivamente garantidor - dos direitos das crianças e adolescentes? Tem sido o juiz um “técnico”, respeitando, nas atuações processuais, as demarcações legais e principiológicas da Constituição Federal e do ECA? Tais perguntas se impõem quando da constatação do largo crescimento das Medidas Socioeducativas de Internação. Mais: a necessidade dos referidos questionamentos se faz sentir pela falta de detalhamento das pesquisas que acabam por aprofundar a condição de invisibilidade da mulher. No bojo dessa invisibilidade, pergunta-se: será que as percepções do magistrado referentes a gênero, tais como “o papel da mulher” e a expectativa sobre este "papel”, decorrentes da estrutura patriarcal da sociedade, são relevantes no momento da aplicação da sentença?

O recorte de gênero se justifica diante das problemáticas patriarcais que apresenta a sociedade brasileira, o que, desde logo, justifica incursões sobre os estudos relativos a gênero e sobre a condição em que as mulheres se encontram.

\section{GÊNERO: UM OLHAR SOBRE AS RELAÇÕES}

A ideia de “direitos iguais à cidadania”, formada no século XIX principalmente no continente europeu e no norte-americano, hoje se mostra como uma das grandes mobilizações feministas que, se não tinha em seu seio ideais radicais, perfez-se, minimamente, enquanto um gérmen do que mais à frente viria a se tornar um movimento organizado de mulheres contra a milenária submissão exercida pelo patriarcado.

Dentro desse movimento de luta pela igualdade de direitos (que incluía o direito ao voto, ao acesso à educação, à aquisição de propriedade, etc.), a questão que será central no pensamento feminista, principalmente após a década de 1960, é, conforme aponta Piscitelli (2011, p. 2), “se a subordinação da mulher não é justa, nem natural, como se chegou a ela e como se mantém?”

Assim, crendo que a subordinação feminina é decorrente das maneiras como a mulher é construída socialmente, restando a ideia subjacente de que o que é construído pode ser desconstruído, as reivindicações feministas voltaram-se para a igualdade no exercício dos direitos, questionando, concomitantemente, quais as raízes culturais de tais disparidades. Para tanto, foi criado o sujeito político coletivo (mulheres), que, em conjunto ao uso de ferramentas teóricas, poderia explicar o azo destas desigualdades.

Deve-se, sobretudo na sociedade capitalista, procurar compreender as práticas sociais (de homens e mulheres) em sua realidade móvel, ambígua e ambivalente, nas dimensões de gênero, 
classe e raça. Assim pode-se entender como a participação da mulher no mercado de trabalho aumenta em concomitância com a persistência da divisão sexual do trabalho: o capitalismo precisa de uma mão de obra flexível que "libere" os homens em geral e as mulheres de classes abastadas (KERGOAT, 2010). Vê-se aqui, inevitavelmente, a confluência entre gênero e classe social - e gênero sob as formas historicamente operantes da dominação masculina.

É, pois, no contexto das relações conflituosas da sociedade capitalista que as problemáticas em torno da mulher precisam ser "lidas" e concebidas sem isolar os conflitos de classe, gênero e raça. Dessa forma, percebe-se como o sistema de punição, imbuído de um discurso sexista, moralista, classista e racista, tem um olhar ainda mais estigmatizante dirigido às mulheres prostitutas, pobres e negras. Na esteira da tendência contemporânea da criminalização em massa, nota-se como as adolescentes, que são os alvos prediletos do Sistema Socioeducativo, congregam em si tais características.

Explica Piscitelli (2011, p. 3) que algumas vertentes do feminismo “apresentam diferenças na percepção das origens e causas da opressão e, também, nos mecanismos considerados apropriados para livrar-se dela. Mas mostram também - e sem pretender homogeneizá-las - que compartilham vários pressupostos”.

A ideia de que as mulheres são oprimidas por serem mulheres, condição que ultrapassa questões de raça e classe, foi necessária para deslocar a luta feminista do pensamento de esquerda, o que levou, em termos políticos, a um reconhecimento da identidade entre as mulheres como condição primária.

Essa identidade ampliou os significados do político no momento em que desenvolveu a ideia de "experienciação" daquilo que é opressivo, derribando uma teoria da opressão meramente objetiva, como preconizava o pensamento marxista, e instituindo uma teoria subjetiva da opressão, bem como a desmistificação da relação de poder inerentemente ligada à esfera pública. Com essa postura, seria possível afirmar que mulheres incluídas em classes opressoras (em termos marxistas), também sofreriam opressão do patriarcado, a partir, exatamente, do que elas "experienciassem” como opressivo.

Importante ressaltar a importância de tais redefinições. Esclarece Piscitelli (2011, p. 6) que

Em termos teóricos, elas [as feministas] trabalharam com uma ideia global e unitária de poder, o patriarcado, numa perspectiva na qual cada relacionamento homem/mulher deveria ser visto como uma relação política. As instituições patriarcais seriam aquelas desenvolvidas no contexto da dominação masculina. Como a dominação masculina estaria presente através do tempo e das culturas, poucas instituições poderiam escapar ao patriarcado. 
O pensamento feminista procurou explicar como o patriarcado se manifestaria nas mais diversas situações, sempre tomando como ponto de partida a ideia de que os homens oprimem as mulheres em escala universal. Ao mesmo tempo que a ebulição acadêmica provocada pelas revisões disciplinares resultou num acúmulo surpreendente de dados sobre a situação da mulher, o que levou, inevitavelmente, a confrontar aspectos das disciplinas humanas, também provocou, em contrapartida, a desestabilização de vários conceitos e categorias com os quais o pensamento feminista operava desde suas primeiras produções.

Dessa desestruturação adveio o crucial questionamento à utilização do termo "patriarcado" enquanto categoria de análise. A crítica perpassava, em resumo, a ausência de apreensão histórica da condição feminina, o que obscurecia a compreensão das relações sociais que organizam diversas formas de discriminação. Em compensação, houve, por parte das teóricas críticas, o reconhecimento da utilidade do termo do ponto de vista de sua mobilização política, na medida em que possibilitou a distinção de forças específicas na manutenção do sexismo, bem como a abertura à argumentação de que a subordinação feminina, ao contrário de ser inevitável, era, em verdade, a naturalização de um fenômeno contingente e histórico (PISCITELLI, 2011).

Sucedeu-se que as hipóteses explicativas da situação de submissão feminina foram postas em cheque, já que baseadas num conceito “trans-histórico”, “trans-geográfico”, “trans-cultural” e “essencializante” (PISCITELLI, 2011). Nesse quadro, surgiram as primeiras teorizações acerca do conceito de gênero. Esta conceituação se desenvolveu no seio dos estudos sobre mulher, compartilhando muito de seus pressupostos. No entanto, havia uma necessidade inerente ao desenvolvimento do estudo, que era superar os problemas relacionados à utilização de determinadas categorias centrais utilizadas nos estudos sobre mulheres.

“O Tráfico das Mulheres: Notas sobre a Economia Política do Sexo”, obra de Gayle Rubin, foi um marco na literatura feminista, ao introduzir o conceito de gênero, imerso no debate sobre as causas da opressão da mulher. Vem de sua produção a elaboração do conceito dos sistemas sexo/gênero, que seriam, in litteris, “produtos da atividade humana histórica” (RUBIN, 2015, p. 23). Ao mesmo tempo que Rubin inova sem precedentes, continua a operar a partir dos pressupostos teórico-metodológicos dos autores em que se baseia, primordialmente, Lévi-Strauss, recaindo numa série de dualismos ainda essencializantes, veementemente criticado por outras autoras feministas, principalmente no ambiente de pós-modernidade.

Entretanto, a construção de Rubin se fez de crucial importância, uma vez que desenvolveu seu estudo como forma alternativa ante o trabalho com patriarcado. Sua elaboração está associada à necessidade de pensar o poder de forma mais complexa e menos monolítica. As principais críticas 
são de cunho epistemológico, entre as quais se sobressai a condenação à construção do conhecimento “ocidental”.

Donna Haraway (2004) salienta que as raízes epistemológicas da lógica de análise implicada na distinção entre gênero e sexo, bem como em cada um deles, deveriam ser historicizadas e relativizadas, atacando a ideia de gênero como identidade global e central. Haraway (2004) assevera, em verdade, que a categoria gênero obscurece todas as outras (classe, raça, nacionalidade), quando teria enorme potencial explicativo e político se fosse historicizada com estas, de tal maneira que as dicotomias universalizantes rebentassem em teorias de corporificação.

Estas críticas foram fortemente influenciadas por teorizações desconstrutivistas, num alinhamento com o pensamento pós-moderno. E falar em pós-modernidade é falar em posicionamentos que

[...] contestam a validade dos modelos que buscam analisar e explicar as transformações históricas pressupondo, por exemplo, a continuidade de certas estruturas e/ou instituições; questionam, também, as abordagens que formulam uma compreensão da diferença tendo como referência um Outro exógeno, externo, procedimento que mantém o princípio de uma unidade e coerência cultura interna; trabalham com uma noção pulverizada de poder, com a ideia de dissolução do sujeito universal autoconsciente, valorizam a linguagem e o discurso como práticas relacionais que produzem e constituem as instituições e os próprios homens enquanto sujeitos históricos e culturais e compreendem, enfim, a produção de saber e significação como ato de poder (PISCITELLI, 2011, p. 14).

Na perspectiva de Judith Butler (1990), expoente dessa leva de desconstrutivistas, gênero se intersecta com diversas outras categorizações constituídas discursivamente, sendo impossível desconectá-lo ou estudá-lo em separado das intersecções políticas e culturais em que é produzido e sustentado. Essa abordagem se contrapõe à ideia rígida de gênero ancorado em bases biológicas, permitindo descrever as múltiplas configurações de poder existentes nos mais diversos contextos históricos, sem pretensões universais.

Acerca deste tema, importante é a contribuição de Danièle Kergoat (2010) disponibilizada em seu texto “Dinâmica e Consubstancialidade das Relações Sociais”, que potencializa o debate até aqui engendrado.

Para a autora, uma relação social é uma relação antagônica entre dois grupos sociais, instaurada em torno de uma disputa. Assim, parte-se do pressuposto de que toda relação social é uma relação conflituosa. Kergoat acredita que segmentar as relações sociais, considerando-as isoladamente, enfrenta paradoxos que, a priori, parecem ser instransponíveis. No entanto, utilizando-se conceitos de consubstancialidade e coextensividade é possível compreender que há uma imbricação, na própria gênese, das diferentes relações sociais, que formam um nó que não 
pode ser desatado no nível das práticas sociais e, por isso, torna-se impossível trabalhar no âmbito de uma única relação.

Kergoat ainda fala que frequentemente misturam-se níveis distintos de realidade, o das relações intersubjetivas e o das relações sociais, o que é um equívoco. Em suas palavras, “as relações intersubjetivas são próprias dos indivíduos concretos entre os quais se estabelecem. As relações sociais, por sua vez, são abstratas e opõem grupos sociais em torno de uma disputa” (KERGOAT, 2010).

Efetuar essa distinção permite compreender, por exemplo, quanto à divisão sexual de tarefas, que apesar de, em nosso microcosmo, ser possível a observação de pequenos avanços, a partir de capacidade de negociação própria das relações intersubjetivas, é preciso ter consciência de que as relações sociais, entretanto, continuam a operar e se manifestar sob suas formas de praxe (exploração, dominação e opressão), muitas vezes veladas por pequenas concessões sistêmicas.

A proposta de Kergoat permite ao intérprete elaborar um método para pensar as relações sociais e seus entrelaçamentos, tanto no que concerne à pluralidade dos regimes de poder como à alquimia que transforma esse tipo de dominação em prática de resistência.

Tal abordagem, associada ao aprofundamento das questões de gênero, da compreensão da não estaticidade das relações sociais, da necessária multiplicidade de vozes do movimento feminista, da derribada dos pressupostos científicos ocidentais, dá-nos poderio de análise quando pautamos a interpenetração, convergências, divergências e problematizações do pensamento feminista ante a criminologia crítica e a dogmática penal - o que será realizado no próximo tópico.

Por enquanto, resta a seguinte consideração: o aumento de internações ${ }^{1}$ suscita indagações e aponta para a necessidade de se promoverem reflexões sobre os fatores desencadeantes desse processo de crescimento da quantidade de adolescentes internadas, ainda que, levando em consideração o universo total de internos, o grupo feminino seja taxativamente a minoria. Perguntamo-nos: será que os magistrados observam tão somente o ato infracional e suas consequências a fim de fundamentar suas decisões ou, abalizados por uma moral patriarcalista, buscam nulificar subjetividades e docilizar mentes? Prossiga-se.

\footnotetext{
${ }^{1}$ Os números do Sistema Nacional de Atendimento Socioeducativo ao Adolescente em Conflito (Sinase) evidenciavam existir no Brasil (2010) 12.041 adolescentes em privação de liberdade, indicando um crescimento em relação ao ano anterior (2009) de 4,50\%. Além disso, no contingente de todas as medidas socioeducativas (seis espécies), existiam no Brasil 40.657 adolescentes infratores cumprindo medidas socioeducativas em meio aberto (advertência, reparação de danos, prestação de serviços à comunidade e liberdade assistida, conforme art. 112, I a IV, do ECA) e 18.107 em meio fechado (semiliberdade e internação, art. 112, V e VI, do ECA), representando uma proporção de dois adolescentes em meio aberto para cada um em meio fechado. Em 2014 já se contabilizavam 20.532 jovens (FBSP, 2014). Pernambuco apresentava um número de 1.473 em meio fechado, dos quais 1.023 eram internos, para 1.637 em meio aberto.
} 


\section{TEORIA DO ETIQUETAMENTO E O PROCESSO DE CRIMINALIZAÇÃO - A ATIVIDADE DAS AGÊNCIAS OFICIAIS DE CONTROLE}

A corrente do interacionismo simbólico ou Labeling Approach (Teoria dos Rótulos ou do Etiquetamento) problematiza o “controle social” como objeto de estudo, no sentido de indicar como o processo de criminalização primária e secundária, desde a perspectiva formal (legislações e instituições) e informal (família, mídia, escola, etc.) é efetivado (como realidade não ontológica), levando em consideração o seu caráter “etiquetador”, seletivo e estigmatizante (BARATTA, 1999).

A Teoria dos Rótulos faz desmoronar as concepções ontológicas sobre o crime. O “essencialismo natural ou sociológico” do desvio não conseguiu resistir à percepção de que a realidade social não é um dado, mas se perfaz como “construto contínuo”. Nessa perspectiva, o delito aparece como um complexo de definições instituídas no seio da dinâmica das relações sociais. O significado necessariamente decorrente disso é a mudança de foco: o desvio não é a qualidade do ato cometido por alguém; ele é a consequência da aplicação, por outros, de regras e sanções a um “ofensor”. Nesse sentido, o comportamento desviante não é absolutamente mais nada além do modo como previamente assim o denominam (BECKER, 1993).

O processo de criminalização na perspectiva interacionista é socialmente sistemático e dinâmico, ao qual concorrem todas as agências de controle formal - o legislador (criminalização primária), a polícia, o ministério público e a justiça (criminalização secundária), e o informal família, escola, mercado de trabalho, mídia. O direito penal, por esse prisma, é apenas parte da estrutura global do sistema, sendo, portando, insuficiente para a compreensão fenomenológica do crime. Ou seja, o fenômeno criminológico tem reverberações a priori e a posteriori ao direito penal. Nesse sentido, os limites do direito de punir (jus puniendi) devem transpassar a faculdade punitiva legislativa (criação da norma) e alcançar a faculdade estatal de persecutio criminis (aplicação da norma). Os limites do jus puniendi devem se estabelecer, pois, concomitantemente, sobre o legislador e o juiz (HORMAZÁBAL MALARÉE, 2006).

Aqui se está no centro da importância de uma criminologia crítica feminista. O lugar das rotulações (as relações sociais dinâmicas) é também a plataforma onde se erigem os pilares representativos e simbólicos da suposta inferioridade da mulher: sociedade patriarcal e capitalista.

O etiquetamento, como marca essencial do sistema penal, ganha forma numa dimensão muito menos palpável do controle: nas ideologias, tanto do saber oficial das ciências criminais, quanto dos operadores do sistema e do senso comum em geral, enquanto senso comum punitivo ideologia dominante (ANDRADE, 2005). 
Assim, tem-se, por um lado, o controle punitivo exercido pelas rotulações robustamente abastecidas pelas ideologias dominantes e, por outro lado, tem-se a mulher como alvo histórico dos símbolos (ideológicos) necessários à realização da dominação masculina. O sistema penal, etiquetador e ávido por punir os rotulados no contexto da hodierna sociedade excludente (sociedade capitalista), encontra a mulher historicamente estigmatizada (pela sociedade patriarcal) e, por isso, “pronta” para o etiquetamento final e ainda mais mortificador (o etiquetamento penal).

Daí, o passo para que a mulher pudesse ocupar o "posto" de alvo do sistema de repressão (comprovado pelas elevadas taxas de prisões femininas) foi só uma questão de tempo.

É de fundamental importância, nesse momento, concentrar esforços no sentido de se evitar fazer uma leitura segmentária da mulher no âmbito da criminologia crítica feminista. Sob tal óptica, chega-se, inevitavelmente, ao questionamento da legitimidade, e conclui-se pela inadequação das instituições de privação de liberdade.

Portanto, o direito penal e o sistema de justiça criminal entram como partes insuficientes, porém envolvidas com os demais meios sociais de criminalização. Importa, pois, compreender, levando-se em consideração o caráter estigmatizante e seletivo do sistema de justiça criminal, o olhar da magistratura no processo de criminalização.

É aqui que a problemática em torno da criminalização da mulher, na perspectiva da criminologia feminista, entra como objeto essencial de análise. Ora, a crítica feminista ocupa lugar importante, contribuindo para a transformação da criminologia nascida no século XIX - como ciência da criminalidade, do criminoso e do crime - na medida em que critica o sistema de justiça criminal, a partir da verificação "de sua complexa fenomenologia e funcionalidade nas sociedades capitalistas e patriarcais” (ANDRADE, 2005, p. 74), no marco da interpretação macrossociológica.

Assim, deve-se voltar o olhar crítico à base material das expressões do patriarcado. Nesses termos, patriarcado passa a ser entendido dentro da complexidade de estrutura sociológica - “[...] patriarcado como um conjunto de relações sociais que tem uma base material e no qual há relações hierárquicas entre homens, e solidariedade entre eles, que os habilitam a controlar as mulheres. Patriarcado é, pois, o sistema masculino de opressão das mulheres” (HARTMANN apud SAFFIOTI, 2005, p. 41).

Sob o prisma da corrente do interacionismo simbólico ou labeling approach e no contexto de uma sociedade marcada pela desigualdade, estruturada em classes e delineada por expressões masculinizantes, pode-se perceber como a

[...] mulher torna-se vítima da violência institucional plurifacetada do sistema, que expressa e reproduz, por sua vez, dois grandes tipos de violência estrutural da sociedade: a violência das relações sociais capitalistas (a desigualdade de gênero) e a violência das 
relações sociais patriarcais (traduzida na desigualdade de gênero) recriando os estereótipos inerentes a estas duas formas de desigualdade, o que é particularmente visível no campo da violência sexual (ANDRADE, 2005, p. 75).

Num momento de elevação no número de encarceramento de adolescentes (e a falta de dados sistemáticos sobre os perfis desse encarceramento), é de se perguntar se a dinâmica patriarcal não tem contribuído decisivamente para esse processo. Daí a necessidade - é a tarefa a que esta pesquisa também se propõe - de realizar a investigação da existência (ou não) de estereótipos do julgador no momento da prolação da sentença, a fim de compreender quais são os valores que têm orientado o controle social formal e informal.

\section{O CAMPO DE PESQUISA: MATERIAL E MÉTODOS}

Em sentido geral, o método é “a ordem que se deve impor aos diferentes processos necessários para atingir um fim dado” (REGIS, 1995, p. 71) ou o “procedimento de investigação ordenado, repetível e autocorrigível que garanta a obtenção de resultados válidos” (ABBAGNANO, 1962, p. 641), cuja importância reside no disciplinamento da pesquisa a fim de excluir o capricho e o acaso, determinando os meios de investigação e a ordem da pesquisa.

O objetivo é analisar vinte e oito sentenças prolatadas no ano de 2010 a 2012, a fim de identificar, por meio da análise de conteúdo (AC), padrões $^{2}$ que as regem - uma abordagem baseada na dedução/inferência, cuja tarefa é a desocultação de significados. Trata-se de uma hermenêutica controlada, baseada na dedução, para possibilitar ao pesquisador encontrar o latente na mensagem.

Neste sentido, a AC parte da exterioridade para o texto, procurando conteúdos de ideologia na linguagem, por meio de um conjunto de instrumentos para o receptor decodificar a mensagem referida a partir do referente (LIMA, 2003).

A prática metodológica advém de uma tradição cientificista que apostava no rigor do método para conferir maior objetividade com pesquisa em textos. Na origem, tratava-se de um conjunto de técnicas, manipuladas com pretensão de neutralidade, que visava à significação profunda de textos, numa nítida tentativa de associar análise qualitativa e objetividade (BARDIN, 1977).

Neste caso, o pesquisador seria uma espécie de “detetive munido de instrumentos de precisão para atingir a significação profunda de textos” (ROCHA; DEUSDARÁ, 2005), e isso

\footnotetext{
${ }^{2}$ As sentenças serão referenciadas com números que funcionam como uma legenda aos casos analisados.
} 
somente é possível porque parte do pressuposto de que existe uma ideia subjacente, realidade que preexiste representativamente.

A AC pode ser quantitativa ou qualitativa: naquela se busca a frequência das características que se repetem no conteúdo do texto, e nesta busca-se a presença ou ausência de dada característica na mensagem. Isto porque o texto é o meio pelo qual o sujeito se expressa, de modo que o analista pode categorizá-lo em unidades, palavras ou frases que se repetem, inferindo algo que represente o conjunto (MUTTI; CEREGNATO, 2006).

As técnicas podem ser múltiplas; no entanto, a que aqui se utilizará é a categoria temática, com a qual se buscam significações detectadas por codificadores. Codificar um segmento é colocálo em uma das classes de equivalência previamente definidas a partir de significações dadas, em função do julgamento do codificado.

Nesse sentido, tem-se o seguinte: definição de codificadores, agrupamento pelo que há em comum e realização de classes de equivalências. Os temas são unidades de registro que agrupam categorias temáticas, as quais, por sua vez, são formuladas no sentido da busca do objetivo pretendido.

É uma espécie de classificação de elementos em diversas caixas, metaforicamente falando, segundo critérios que apresentem um sentido, uma vez que na AC o interesse não é o da descrição, mas o que os conteúdos podem anunciar após serem tratados. A análise, desse modo, é realizada em grelhas, nas quais se preenche uma informação simbolizada pelo indicador.

Devido às inferências, recorre-se a indicadores (quantitativos ou não) sobre o emissor da mensagem e que são colocados em evidência para compreender: o que conduziu o emissor a determinado enunciado? Quais as consequências do enunciado? - elementos denominados de “condições de produção”, os quais podem apresentar variáveis psicológicas, sociológicas e culturais (BARDIN, 1977, p. 41).

Considerando que o objetivo é identificar representações de magistrados sobre a medida socioeducativa de internação, nada melhor do que compreender os discursos que permeiam o texto.

É importante compreender discurso como uma espécie de vontade de verdade em que se põe em jogo o poder e o desejo de se dar a última palavra (BOURDIEU, 2010), para garantir a legitimidade do ato decisório, enquanto provedor de justiça (DERRIDA, 2010).

O discurso, como manifestação da representação social, não se confunde com simples texto; vai além, é uma peça de oratória para a persuasão, uma ponte entre o pensar e o falar; o pensamento revestido de signo que se torna visível pelas palavras para produzir um sentido. Uma violência de imposição de verdade (FOUCAULT, 2010). Ou seja, a questão é compreender o que 
está oculto no texto e que reflete códigos ideológicos do julgador, num estudo exploratório, descritivo e qualitativo de documento.

Diante do que foi dito, o que se pretende é compreender as representações da magistratura pernambucana sobre gênero no momento da imposição da medida socioeducativa de internação, e, ao se entender essa rotina, poder-se-á organizar melhor ou até mesmo aperfeiçoar a prática jurídica, no caso de constatação de incongruências legais.

Representação é “algo que alguém nos conta sobre algum aspecto da vida social” (BECKER, 2009, p. 18), seja comum, elaborada nos atos mais simples da vida cotidiana, seja mais elaborada, preparada com preocupação de cientificidade. São informações que orientam as práticas e relações humanas, construídas por meio de comunicações sociais e apreendidas socialmente (MOSCOVICI apud ANCHIETA; GALINKIN, 2005), além de variar em função dos extratos econômicos e culturais em que se inserem os indivíduos ou grupos (PORTO, 2006).

As representações sociais funcionam como princípios orientadores e indutores de condutas, seja de indivíduos, grupos ou instituições, de modo que compreender como a magistratura representa as medidas socioeducativas de internação importa desvendar o que se pensa sobre o instituto, captando seus significados, expondo seus sentidos.

Obviamente que não cabe aqui fazer a reconstituição do conceito das representações sociais, tão próprio da psicologia social, mas é importante deixar clara a premissa de que inexiste ruptura entre o mundo interno e externo e entre o sujeito que representa e o objeto representado e, acima de tudo, de que a realidade é simbolicamente construída pelos atores sociais a partir de suas projeções cognitivas e sentimentais, as quais indicarão as predisposições de condutas diante do que se analisa (NASCIMENTO-SCHULZE; CAMARGO, 2002).

As representações sociais são teorias implícitas sobre objetos sociais e têm a função de organizar o significante do real, pois emergem do contexto social, elaboradas a partir de um quadro de apreensão de valores, ideologias e sistemas de categorização social partilhado pelos grupos sociais e que se constituem e circulam pela comunicação, refletindo as relações sociais, ao mesmo tempo que contribuem para sua produção (VALA, 1986).

Os estudos sobre representações buscam compreender a forma pela qual as pessoas elaboram crenças, teorias e atitudes sobre a realidade social, com o objetivo de construírem um mundo significante, a partir das interações sociais (SÁ, 2002); de modo que é possível compreender a sociedade como um sistema pensante, tal como um sistema econômico, cultural... Um exemplo disso são os estereótipos - crenças largamente partilhadas que associam categorias e atributos (VALA; CASTRO, 2013). 
Desse modo, o estudo da representação social da magistratura sobre o gênero das adolescentes em conflito com a lei não se dirige aos juízes, mas aos conteúdos que eles simbolizam. O magistrado, ausente enquanto tal, está presente como expressão de padrões de organização social, de modelo de comportamento interpessoal e de um certo tipo de saber. O quadro organizacional de que se fala, medida socioeducativa de internação, está associado a modelos de comportamentos interpessoal que nele se inspiram e se reproduzem. Enfim, a representação social do magistrado veicula um modelo do homem e da sociedade.

Sim, porque

[t]odo campo social desenvolve uma doxa, um senso comum, e um nomos, leis gerais que o governam. O conceito de doxa substitui, dando maior clareza e precisão, o que a teoria marxista denomina "ideologia”, como "falsa consciência”. A doxa é aquilo a respeito do que todos os agentes estão de acordo [...]. Nesse sentido, a doxa contempla tudo aquilo que é admitido como "sendo assim mesmo": os sistemas de classificação, o que é interessante ou não, o que é demandado ou não. Por outro lado, o nomos representa as leis gerais, invariantes, de funcionamento do campo. Tanto a doxa como o nomos são aceitos, legitimados no meio e pelo meio social conformado pelo campo. (AZEVEDO, 2010, p. 121)

Nesse momento, as representações sociais podem contribuir para retirar da clandestinidade as dimensões culturais e subjetivas que interagem com o campo social, funcionando como poderoso guia de ação, seja para legitimar políticas de prevenção e combate à criminalidade, seja para a justificativa da intervenção institucional violenta, e até das respostas vindicativas privadas.

Nesse sentido, é imprescindível compreender a rede de forças, o mosaico de práticas e políticas que atuam nas formas de resposta ao crime, uma vez que a identificação dos interesses e dos significados culturais que amparam essas novas práticas permite compreender as racionalidades, os discursos e as retóricas que influenciam as decisões.

No caso da magistratura,

La presencia del significado simbólico en las formas cotidianas de la acción penal pragmática se observa con mucha facilidad si tomamos en cuenta la práctica de dictar sentencias. Al “emitir la sentencia” el juez realiza una rutina, una acción instrumental que activa un proceso legal subsecuente. Realiza un decreto-discurso - te sentencio a tres anõs de prisión - que en la práctica significa autorizar y poner en marcha un procedimiento de encarcelamiento. Dictar una sentencia es, por lo tanto, un elemento operativo en un proceso instrumental de enfrentar a los infractores. Pero el citado de la sentencia también transmite una aseveración simbólica que interpreta y comprende un amplio público (o públicos) fuera del tribunal (GARLAND, 1999, p. 60).

Com essa perspectiva trazida pelas representações sociais, reinsere-se a discussão das crenças e dos valores, o papel da subjetividade nos dispositivos decisórios, encobertos pelos mantos (irreais) da neutralidade e da imparcialidade, por meio de produção de conhecimento relevante e válido (FREIRE; AZEVEDO, 2013). 
Evidentemente, a busca pela representação depara-se com limites. Por exemplo, as narrativas escritas omitem elementos visuais da experiência, e o que vem após a cessação da investigação não é informado, de modo que não se pode assegurar, por completo, a descrição do objeto que se pretende compreender (BECKER, 2009).

Antes de adentrar a análise dos dados, cumpre justificar o quantitativo de vinte e oito sentenças. Na verdade, há uma defasagem de dados e controle de fluxo de entrada e saída de adolescentes, não somente em Pernambuco, mas em todo o País. Essa problemática já foi identificada pelo governo federal, que vem implementando o Sipia-Sinase, um sistema de informação em rede de abrangência nacional para a formação de um banco de dados único, visando ao "registro e tratamento de dados referentes a adolescentes em conflito com a lei em cumprimento de medidas socioeducativas” (ONDCA, 2014). Porém, tudo ainda está em construção.

Isso significa afirmar que, pelo menos no estado de Pernambuco, não há informação da quantidade de sentenças de aplicação de medida socioeducativa de internação que foram prolatadas para adolescentes do sexo feminino em determinado ano.

A solução para a definição de uma amostra $^{3}$ foi utilizar as sentenças de adolescentes que estavam cumprindo medida socioeducativa de internação no Centro de Atendimento Socioeducativo (Case) Santa Luzia até abril de 2012, momento no qual teve início a pesquisa etnográfica da primeira autora, na unidade, durante o doutoramento. Na verdade, existiam 35 adolescentes; porém, sete delas estavam na modalidade de internação sanção ${ }^{4}$, a que não compõe o universo da pesquisa.

Assim, foram analisadas as 28 sentenças disponíveis, formando o “universo” de pesquisa 5 .

O critério de escolha foi amostral, definido conforme as possibilidades de pesquisa, e apenas se vinculou ao período em que a primeira pesquisadora visitou a unidade de internação. É importante esclarecer que as sentenças são proferidas por juízes de diversas comarcas do estado de Pernambuco e que os processos de execução são reunidos na única vara de execução localizada em Recife, onde os processos foram disponibilizados.

Enfim, a pesquisa é eminentemente qualitativa, com o objetivo de ver por meio dos olhos daqueles que são pesquisados, compreender as interpretações que eles têm de mundo, exatamente

\footnotetext{
${ }^{3}$ Devido à inexistência de um universo definido, não se pôde identificar a representação amostral.

${ }^{4}$ Trata-se de uma hipótese autorizadora da medida socioeducativa de internação devido ao descumprimento de uma medida anterior mais leve. Por não se tratar de sentenças que avaliam o ato infracional, e sim do descumprimento da medida anterior, fogem do objeto de pesquisa, deixando de entrar na análise.

${ }^{5}$ Importa esclarecer que não foi possível identificar o número do processo da sentença 22, sendo esta apresentada como "sem número". As sentenças 18 e 19 são de duas amigas julgadas nos mesmos autos, assim como as de número 26 e 27, que são de duas irmãs, razão pela qual têm números iguais.
} 
porque são essas que motivam o comportamento que cria o próprio mundo social (BAUER; GASKELL, 2002).

Por razões didáticas as sentenças serão referenciadas no corpo do texto conforme a seguinte numeração apresentada no anexo.

\section{RESULTADOS E DISCUSSÕES: ESTEREÓTIPOS E DESTINO DE ADOLESCENTES}

Os resultados serão apresentados em categorias, as quais terão a indicação das respectivas frequências em que o elemento foi utilizado no universo da amostra.

Essas categorias são reuniões dos fundamentos justificadores da medida socioeducativa de internação. Obviamente que diversos olhares interpretativos podem ser utilizados. No entanto, considerando que o recorte teórico aqui utilizado diz respeito às questões de gênero, é esta a lupa de análise. Além disso, diversas passagens podem ser classificadas em uma ou outra categoria, o que implica afirmar que a frequência aqui extraída não é exata, mas meramente aproximativa.

\subsection{VIVÊNCIA FAMILIAR: O CONTROLE SOCIAL INFORMAL DO FEMININO}

A necessidade de reforço familiar foi o argumento de $36 \%$ das sentenças. Isto é, a consideração pelo magistrado de que a medida socioeducativa de internação seria útil em termos de reconstrução dos vínculos familiares - porque, além de tê-los como deficientes, acreditou que a solidificação dos mesmos ensejaria um maior controle sobre as adolescentes - foi o fundamento justificador da medida. Em alguns momentos, expressões bastante genéricas aparecem, o que dificulta entender, mesmo levando em consideração o contexto da fala, o significado ou sentido de tais expressões.

Não obstante a dificuldade, esse raciocínio pode ser percebido nesses extratos: “o núcleo familiar não tem condições de recebê-la para fins de tratamento” (Sentenças 1 e 7); há “inexistência de referencial familiar” (Sentença 3); os pais “não tem controle sobre a filha” (Sentença 8); e “não há a devida fiscalização e observância de seus genitores” (Sentença 7).

Aqui, percebe-se claramente, por parte dos magistrados, uma concepção sobre família. Por meio de um discurso que, ao transpassar o ato em apreciação, absorve, manifesta e legitima um modelo estereotipado de família.

Tais modelos têm como âncora o comando dos genitores (sobretudo do pai) sobre os filhos (especialmente sobre as filhas). Nesse sentido, e com base no senso comum dos magistrados, a ideia 
de família deve corresponder, necessariamente, às percepções de “controle”, “condições de impor limites” e “predisposição fiscalizadora”. Veja o exemplo abaixo:

A desagregação familiar é o fator preponderante nessa escalada da violência juvenil. Há de forma generalizada não só nas camadas mais pobres da população um total descompromisso com os valores fundamentais da família e suas benéficas consequências para o progresso social (Sentenças 18 e 19).

Importante notar que o arranjo familiar perpassado por esses valores tradicionalmente aceitos tem como estrutura fundante relações baseadas na autoridade, e esta encontra o seu ponto de realização fenomenológica, ao logo do percurso histórico, na figura do homem. À mulher, e mais ainda à filha adolescente, resta a supervalorizada virtude, de cunho patriarcal, da obediência, da docilidade, da submissão.

Porém, como foi referenciado acima, a maioria das adolescentes consideradas em conflito com a lei não tem um modelo de família que atenda, integralmente, aos requisitos da tradição. Quando o julgador percebe isso, compreende de pronto que lhe cabe, além de julgar o ato ilícito, assumir esse "lugar de poder”, para por “ordem” àquilo que, a seus olhos, é desordem familiar. Veja um outro trecho elucidativo:

\footnotetext{
A adolescente infratora não possui o manto da autoridade dos pais. Como se vê tem um irmão preso por dois homicídios, também com o envolvimento com tráfico de drogas; o que demonstra à toda evidência, o desajuste familiar, ficando a menor à mercê das práticas ilícitas, sendo necessária a intervenção estatal por ora pra tirá-la do seio social, visando sua proteção integral (Sentença 17).
}

Um detalhe importante é que algumas vezes a conduta da adolescente seria, de per si, suficiente para, legalmente, ser imputada a medida de internação - como no caso de ato infracional análogo a subtração de coisa móvel alheia, mediante grave ameaça (Sentença 16) -, e, mesmo assim, o magistrado sente a necessidade de “desqualificar” a família da representada como forma de “acúmulo” de argumentos para fixação da medida.

Nesses termos, as recorrências ao conceito e ao modelo tradicional de família para impor a medida de internação revelam um desejo de perpetuar o controle por vias da autoridade, sobretudo masculina, como forma de disciplinamento daqueles aos quais, historicamente, o controle e a subordinação se dirigiram: em especial, a mulher.

A adolescente em conflito com a lei, ao demonstrar por meio de seus atos, em estado de consciência ou não, rebeldia ao "lugar" que foi reservado à "mulher de família”, torna-se mais vulnerável à eufêmica medida de internação. O discurso de proteção à família oculta o desejo moralista e conservador de proteção da família patriarcal e capitalista, por vias do controle da 
adolescente e, especialmente, de sua sexualidade. Assim, como diz Vera Regina Pereira de Andrade (2005, p. 98):

E a função reprodutora (dentro do casamento) se encontra protegida sob a forma da sexualidade honesta, que é precisamente a sexualidade monogâmica (da mulher comprometida com o casamento, a constituição da família e a reprodução legítima), de modo que protegendo-a, mediante a proteção seletiva da mulher honesta, protege-se, latente e diretamente a unidade familiar e, indiretamente, a unidade sucessória (o direito de família e sucessões), que, em última instância, mantém a unidade da própria classe burguesa no capitalismo.

Enfim, a fragmentação familiar da adolescente recai como estigma a macular a imagem da jovem, sendo internada não exatamente pela infração cometida, mas enquanto mártir de punição de eventuais inadequações sociais dos que formam sua família e de como ela se comporta diante desta.

A ideia de uma jovem independente e minimamente distante dessa organização social nuclear aparentemente necessária - a família - parece incomodar a visão patriarcalista, que sempre reservou à mulher o papel secundário e privado no seio social. À mulher restariam as virtudes da benevolência, docilidade e submissão, qualidades biologicamente designadas ao ser feminino, a serem repassadas especialmente à figura da filha.

Nem mesmo se discute a motivação do distanciamento da jovem do seio familiar, apenas elenca-se sua participação enquanto necessária e, portanto, sua ausência enquanto característica deficitária, capaz de ensejar sua internação, sem maiores digressões, argumentando a aplicação da medida pela "inexistência de uma figura de autoridade que exerça um papel de vigilância” (Sentença 15). O trecho a seguir ilustra ainda mais essa reflexão: "Como se não bastasse, a investigada encontra-se nesta cidade sem qualquer acompanhamento de seus familiares, segundo uma das testemunhas ouvidas - Conselheira Tutelar [...]” (Sentença 12). Ou seja, por que uma jovem, com filho recém-nascido - como é o caso da adolescente referida na sentença em questão -, estaria sem qualquer acompanhamento?

Observe-se ainda o trecho seguinte, em que a jovem é punida por seu arranjo familiar:

[...] há de se levar em consideração as repercussões pessoais e sociais da conduta ora apurada [...]. A. S. M. d. S. é contumaz em prática infracional de mesma natureza, reincidente na [...] e no Centro de Internação Provisória, já foi beneficiada com Remissão e submetida às medidas socioeducativas em meio aberto [...], tem quatro irmãos envolvidos em práticas ilícitas e um filho recém-nascido (Sentença 9).

Enfim, o poder exercido sobre as mulheres é reflexo de fundamentos ideológicos e não naturais, e condiciona a repartição dos recursos e a posição superior de um dos sexos (BARATTA, 1999b), estabelecendo, assim, limites específicos para as mulheres exercerem sua cidadania e autonomia. 


\subsection{COMPANHIAS: “DIGA-ME COM QUEM ANDAS QUE TE DIREI QUEM ÉS” - ESTEREÓTIPO DA SUBJETIVIDADE E DO LUGAR DO FEMININO}

O ditado popular que guarda em si suas sabedorias foi, não exatamente com essa expressão, mas com a mesma indicação de conteúdo, utilizado em 93\% dos casos.

Aqui, o magistrado aplica a medida socioeducativa de internação devido às companhias com as quais a adolescente convive - pessoas consideradas inescrupulosas -, na presunção de que a adolescente, vulnerável, estaria sendo manipulada e influenciada pelas más condutas, razão pela qual o encarceramento ser-lhe-ia útil, para que ela pudesse se afastar desses círculos de amizade.

Não somente, o magistrado claramente usa estereótipos do que considera feminino, de modo que a subjetividade, o lugar e também o que faz a adolescente são elementos de apreciação do olhar padronizado do magistrado.

A tentativa de limitar as relações extrafamiliares das representadas por meio de expressões gerais e sobrecarregadas de valores pode ser identificada nas seguintes situações: "estreita relação" das adolescentes “com grupos de riscos e pessoas de caráter inidôneo” (Sentenças 3 e 8).

Tal constatação aponta que, para além da gravidade das condutas, os círculos de amizades corroboraram para embasar e determinar a aplicação da medida de internação às representadas. Para os magistrados, o "controle" deve extrapolar os limites dos lares, alcançando as "ruas" e visando à reorientação das relações. Ressalte-se que os critérios de orientação para seleção e celebração de amizades são, na esteira da sociedade patriarcal, muito mais rígidos para as adolescentes. No contexto da justiça isso fica evidente quando "as companhias” das representadas são perscrutadas, rotuladas e desqualificadas para, posteriormente, servirem como "razões de internação”.

A categoria aqui discutida revela que a tutela estatal extrapola todos os limites objetivos circunscritos pela conduta das adolescentes e busca alcançar e regrar o que há de mais íntimo nelas: os sentimentos, os afetos, o estado de espírito e a personalidade. O nascedouro desse tipo de domínio das interioridades é a compreensão estereotipada (superficial e ideológica) acerca da “natureza” da mulher: ao feminino exige-se meiguice, afetos, carinhos, emoção, sentimentos refinados e espírito dócil. A adolescente em conflito com a lei que não corresponde à regra torna-se ainda mais vulnerável à medida socioeducativa de internação.

Assim, em umas das sentenças analisadas, o magistrado informa que, uma vez comprovada a autoria e a materialidade da conduta, irá passar à avaliação da medida socioeducativa mais adequada, e prossegue dizendo que "a adolescente tem dificuldades de demonstrar seus afetos, agindo na superficialidade dos sentimentos, apresentando-se fria e indiferente em situações que requerem expressões de emoções” (Sentença 8). Noutro processo, o juiz, no momento da definição 
da medida, diz que a adolescente "perante a autoridade policial cantou e assoviou durante alguns trechos da oitiva (demonstrando frieza e qualquer [sic] sinal de remorso, bem como desprezo pela vida humana)” (Sentença 6). Tais falas evidenciam um olhar fixo e predeterminado que invade interioridades, questionam as diferenças e fundam subjetividades com base no - senso comum socialmente aceito.

Nesse mesmo sentido arremata, em outras sentenças: “[...] resistência a submissão de regras e limites [sic], uso de substâncias psicoativas, conduta absoluta e independente, fragilidade e inabilidade responsável na conduta do processo educativo, bem como na imposição de limites e normas” (Sentença 14); “[...] personalidade desregrada” [,] “mau comportamento e a necessidade de ser monitorada mais de perto” (Sentenças 12 e 14).

Aliás, considerando que a criminologia afirma que o direito reproduz desigualdades como mecanismo de reprodução da realidade social, entende-se que a força da ordem masculina sobrepuja a feminina e aparenta a normalidade, em que “a visão androcêntrica impõe-se como neutra e não tem necessidade de se enunciar em discursos que visem a legitimá-la” (BOUDIEU, 2003, p. 75).

Esse contexto leva à reflexão de que, rotineiramente, cabia ao sexo feminino, no máximo, o papel de vítima, dada a representação de “um ser frágil, doméstico, dependente, [que] pouco ou nenhum perigo oferecia ao direito penal. O papel de cometer crimes cabia ao homem sujeito ativo, dominador e perigoso. À mulher restava a fragilização das vítimas” (MELLO, 2007, p. 446).

Porém, quando esta mulher - e, no caso específico, as adolescentes - passam a assumir protagonismo no delito, deve-se buscar uma compreensão de como a dinâmica patriarcal se operacionaliza para que o controle da subjetividade feminina seja garantido. Observem-se alguns trechos a seguir: “[...] ausência de limites para mensurar os atos que comete” (Sentença 7). “[...] comportamento rebelde e transgressor [da representada]” (Sentença 3). “[...] fragilidade e inabilidade responsável na conduta do processo educativo, bem como na imposição de limites e normas [...], falta aos adolescentes imposição de limites e normas por parte dos responsáveis [...]” (Sentença 14). E ainda:

A adolescente, apesar de primária na UNIAI, faz uso de drogas lícitas e ilícitas, abandonou
os estudos, seus pais são falecidos, reside com um amigo, não conta com uma figura
representativa de autoridade, refratária a limites e orientações, além de estrita ligação com
grupos de riscos e pessoas de caráter inidôneo (Sentença 23).

Além do controle da subjetividade, o controle do local deve ser também garantido, pois não é a rua, mas a casa, com suas respectivas ocupações, que deve ser modulada no papel feminino: “[...] não estuda nem trabalha, possui íntimo envolvimento com pessoas inidôneas”; “[...] já foi beneficiada com Remissão e submetida às medidas socioeducativas em meio aberto”; “[...] não 
tendo surtido o efeito esperado, possui vivência de rua” (Sentença 9). “[...] há constatação de vivência nas ruas”; “[...] os laços efetivos estão fragmentados pelo histórico da adolescente na rua [...]”; “[...] a representada vive na ociosidade e fazendo uso da mendicância” (Sentenças 2 e 3). "Há ainda que levar em consideração que falta aos adolescentes imposição de limites e normas por parte dos responsáveis, estando os mesmos fora da escola e apresentarem [sic] vulnerabilidade social extrema” (Sentença 14).

Enfim, a socialização é dada a partir do gênero, de modo que cabe à menina a valorização das relações domésticas, de amizade, de lealdade e de serviço ao companheiro, sendo sua identidade construída no âmbito doméstico, numa espécie de “código da casa” (BREITMAN, 1999).

Isto é, a mulher cumpre papéis específicos, cujos atributos são vinculados às atividades relativas à vida privada nas relações sociais, sendo, portanto, subordinada ou inferiorizada. Nesse sentido, a mulher é construída como “uma criatura emocional/subjetiva/passiva/frágil/impotente/ pacífica/recatada/doméstica/possuída” (ANDRADE, 2005, p. 85).

Nem se perquire a razão pela qual a adolescente estaria nas condições sociais em que são julgadas. Apenas as valora negativamente, como nestes casos: “[...] a representada tem 16 anos e se encontra em situação de extrema vulnerabilidade social” (SENTENÇA 3). “Todavia, percebe-se que a situação de extrema vulnerabilidade social e pessoal [...].” (SENTENÇA 9).

Há ainda situações em que não se debate o grau de vitimação das adolescentes, normalizando agressões praticadas contra as mesmas, como se elas tivessem que suportá-las inertes. A ideia de sublimação parece fazer parte da feminilidade, segundo o imaginário dos magistrados.

Veja um caso de duas irmãs que eram agredidas pelo tio: “[...] o ato infracional revela grande gravidade, visto que houve premeditação e promessa de recompensa, além de que a vítima era parente das representadas. E, apesar de serem primárias, agiram de modo por demais reprovável” (Sentenças 26 e 27).

Em outra situação, a adolescente era namorada de um traficante, porém ameaçada por ele, relato confirmado por testemunha; e, no momento que vai ao encontro dele, segundo narra a adolescente, ele exige a prática de ato sexual. Diante da recusa, tem que dormir com “facão”, que seria usado para exigir a relação logo ao amanhecer do dia. Ela, para se defender, mata-o, como seguramente confessa (Sentença 13).

Outra situação tem como única prova (além da perícia tanatoscópica) a testemunha de acusação, cujo depoimento aponta que “a vítima estava embriagada e viu quando foram a tapas, que a vítima estava dando uma gravata na representada, socos no rosto e dois homens tiveram que separar” (Sentença 21). Porém, sem discutir eventual forma de defesa, a magistrada aponta que o 
homicídio “é bárbaro” (como se a violência sofrida pela adolescente também não fosse...) e complementa: “A adolescente demonstrou tranquilidade no momento da confissão, declarando com extrema frieza todos os detalhes da prática do bárbaro ato infracional, tendo dito que em momento algum se arrependera do cometimento do ato” (Sentença 21).

Parece que, na avaliação do magistrado, a adolescente deveria estar desesperada e arrependida, características estereotipadas sobre a subjetividade feminina.

Uma outra forma de controle da subjetividade da adolescente é percebida quando o ato é praticado em concurso de pessoa e a vítima é homem. Nesses casos, o papel da menina é partícipe, e, segundo a interpretação judicial, coube a ela seduzir a vítima, ex-companheiro, viciado em drogas e devedor da boca de fumo do atual namorado (Sentenças 18 e 19).

Aqui há uma presunção (sem qualquer outra prova que a corrobore) que a mulher funcionou como uma isca para a emboscada. Há o imaginário de que ela exerceu a sedução, uma presunção que deriva do estereótipo do papel feminino - o envolvimento pelo corpo e pela sexualidade. Mesmo que inexista prova que confirme a representação do magistrado quanto a esse papel feminino.

Na situação, não é explícita a referência à sexualização, e não há provas suficientes de que a adolescente teria "atraído a vítima para a emboscada”. Contudo, o magistrado faz uma simples ilação entre a adolescente ser ex-namorada da vítima e ter passado o dia com ela "consumindo bebida alcoólica”.

É interessante que a única testemunha é de acusação e é indireta, pois “soube por comentários” que a vitima é traficante na comunidade e “que sempre avista as representadas juntas” (Sentenças 18 e 19). Isso é suficiente para que a adolescente seja tida com culpada.

Semelhantemente, em outra situação, não há descrição da conduta das adolescentes, não há testemunhas e há “diversas contradições nos depoimentos”, porém se presume que a adolescente participou do homicídio porque “a representada é namorada do suposto autor do delito” (Sentença 28). Somente por isso.

Enfim, a violência desses discursos são reais e simbólicas: aprisiona-se um corpo, indesejável no seio social, e aprisiona-se uma subjetividade, uma forma de ser no mundo, que, consciente ou inconscientemente, pode denotar uma existência (ou resistência) que subverte padrões (im)postos.

Além disso, o que é o período da adolescência senão um momento de autoafirmação, por vezes mediante atitudes que lembram “rebeldia” e “inadequação”? Resta saber por que alguns (algumas) rebeldes caem na malha dolorosa do sistema punitivo enquanto outros(as) são 
“tratados(as)” de forma bem mais compassiva. Afinal, restam poucas formas de "ser no mundo" à menina futuramente reclusa. O Estado parece dizer: "seja! (desde que nos moldes que prescrevo)”.

Sobre tal tema, discorre Raúl Zaffaroni (1999, p. 119):

Seja qual for a perspectiva a partir da qual se queira fundamentar o direito penal do autor (culpabilidade de autor ou periculosidade), o certo é que um direito que reconheça, mas que também respeite a autonomia moral da pessoa, jamais pode penalizar o 'ser' de uma pessoa, mas somente o seu agir, já que o direito é uma ordem reguladora de conduta humana. Não se pode penalizar um homem [ou mulher] por ser como escolheu ser, sem que isso violente a sua esfera de autodeterminação.

Siga-se à última categoria.

\subsection{HISTÓRICO: MENINA, TEU PASSADO TE CONDENA. UM OLHAR RETROSPECTIVO E PRECONCEITUOSO}

Nessa, o magistrado, após constatar a materialidade e a autoria da conduta, percebe que não pode aplicar a medida de internação com base na gravidade do ato da representada, e assim, atendendo aos anseios do Ministério Público, opera o seguinte devaneio jurídico-discursivo (Sentença 7):

A natureza do ato, por si só, não enseja aplicação da medida de internação. Entretanto diante do que foi apurado durante a instrução processual, em face do histórico de desenvolvimento da representada em outros atos infracionais e em conformidade com o parecer ministerial, aplica-se a medida de internação.

Não por coincidência, as mesmas adolescentes que tiveram suas sentenças contempladas na categoria acima viram-se diante de outros argumentos - igualmente ilegítimos e frágeis -, de modo que é possível afirmar que, se não existem atos delituosos graves a serem corrigidos (punidos) pela medida de internação, busca-se legitimidade para a mesma nas ideologias de defesa (para “afastar” o “perigo pessoal”), nas condutas pregressas (para “corrigir” o "histórico da adolescente”) e nos laudos psiquiátricos (para “curar” os “distúrbios mentais”).

A impressão que fica é de que parece não haver saída - a adolescente que não atende à expectativa do magistrado, descumprindo o papel que a sociedade lhe reputou devido (de boa moça, recatada e obediente), perderá, por um motivo ou outro, a sua liberdade; afinal, sua anormalidade leva à tendência à prática do crime, como foi encontrado em $12,5 \%$ das sentenças, e como pode se observar a seguir: “A representada é pessoa com tendência à prática de ato infracional, sendo imperativa a sua retirada da comunidade onde vive, justificando a aplicação da medida socioeducativa de internação [...]” (Sentença 16). "Este Juízo, em virtude das condições de vida 
dos representados, que já estão inseridos num contexto de delinquência, entende que deve ser aplicada a medida de internação [...]” (Sentença 15).

Isto é, a interpretação retrospectiva, eivada de subjetivismos, dá-se da seguinte forma: os atores jurídicos realizam um processo por meio do qual reinterpretam o passado comportamental da adolescente à luz da nova informação concernente ao desvio. Estes reveem o passado de interações da adolescente em questão, procurando por sutis pistas e nuances de comportamento transcendente aos papéis atribuídos que podem dar mais uma prova do alegado desvio (SCHUR, 1971).

Logo, o histórico da adolescente torna-se fundamento da medida socioeducativa de internação, como foi o caso de $25 \%$ das sentenças:

A natureza do ato, por si só, não enseja aplicação da medida de internação. Entretanto diante do que foi apurado durante a instrução processual, em face do histórico de desenvolvimento da representada em outros atos infracionais e em conformidade com o parecer ministerial, aplica-se a medida de internação [...] (Sentença 7).

E: “As testemunhas arroladas pelo MP foram uníssonas em afirmar que a representada praticava de forma reiterada o ato infracional do mesmo tipo, subtraindo motocicletas utilizando-se do mesmo modo criminoso [...] (Sentença 16).

Enfim, o sistema de justiça criminal, especialmente na pessoa do magistrado - sujeito que materializa as perversidades abstratas do macrossistema - e conforme denunciado por Andrade (2005), utiliza-se de elementos referentes à personalidade da mulher, aos grupos em que convive, ao seu estado emocional e psíquico, à sua vivência escolar, comunitária e familiar com o "simples" propósito de fundamentar não apenas a decisão em si, como também a escolha do tipo de medida e seu grau de gravidade.

São as pistas e nuances antes referidas; são os indícios necessários - assim significados conforme a vontade do agente significador -; são as falaciosas ideias de que o juiz, paladino dos fracos e oprimidos, pode suplantar eventuais deficiências na socialização domesticadora que o patriarcado procura imprimir por meio de todas as suas agências de poder.

\section{CONSIDERAÇÕES FINAIS}

Como se viu, este simbolismo de gênero tem uma poderosa carga estigmatizante, com tendência a naturalizar comportamentos mediante determinismos biológicos. Como o sistema de justiça criminal está imerso na lógica estigmatizante arquitetada nas relações sociais, este expressará e reproduzirá esse mesmo simbolismo de gênero nos processos de etiquetamento. 
O desvio dos papéis (personas) determinados aos indivíduos resulta em sua apreensão pelo sistema, de modo que não é o fato que orienta a responsabilização, mas sim o sujeito que pratica a conduta, não nos olvidando das problemáticas referentes à classe, raça, etc. Dessa forma, o sistema de justiça criminal funciona como um mecanismo público de punição àquelas meninas que escapam ao controle informal feminino, reforçando o controle patriarcal ao criminalizá-las em situações específicas, notadamente naquelas em que transcendem o ethos reservado ao papel feminino.

Nesses casos, a adolescente não será responsabilizada pela suposta infração que cometeu, mas em razão do acaso da vida ou do destino de ter nascido no lugar em que nasceu, por ter a família que tem, por se identificar com o gênero feminino, por ser quem ela é e, possivelmente, por não corresponder àquilo que a sociedade imputa como ideal, numa infeliz tentativa de reenquadramento de personalidade e normatização de corpos.

Isso não só muitas vezes flexibiliza, como também pode vir a sequestrar por completo as garantias fundamentais, sob o mascaramento da retórica socioeducativa, marcadamente maculada por percepções moralistas. Isso se torna um acinte aos ideais cristalizados num Estado democrático de direito, tornando a práxis jurídica algo odioso.

Se o sistema de justiça criminal, consoante demonstra Vera Regina (2005), é formado por três dimensões, sendo uma delas a dimensão normativa e institucional-instrumental em que são abarcadas as três esferas de Poder do Estado democrático de direito, quais sejam, Legislativo, Executivo e Judiciário, constata-se que os representantes estatais, mormente os incluídos no aparato do Poder Judiciário, ainda que sob o baluarte dos conceitos de igualdade e justiça formadores de modelo estatal, não estão totalmente escusos da reprodução de todos os estereótipos e conceitos estigmatizantes a que são submetidas as adolescentes quando identificadas pelo sistema punitivo.

Ora, compreende-se que a medida, embora teleologicamente socioeducativa, possui caráter de responsabilização diferenciada, sem, por posição político-jurídica, abarcar as penosas contradições que o reconhecimento de uma natureza penal poderia trazer. No entanto, as lógicas operacionalizadoras do sistema punitivo do adulto encontram espaço também na práxis do sistema socioeducativo, ainda mais quando os agentes judiciários, agentes estes que dão a real efetividade à sede punitiva deflagrada na órbita legislativa, "bebem” da mesma fonte opressora e exploradora presente em nossa sociedade racista, machista, classista, homofóbica e transfóbica (dentre outros marcadores de opressão).

Isso é potencializado quando se observa haver ainda dificuldade de assimilação da mudança paradigmática pelo imaginário social e pelos representantes do Poder Judiciário e seus atores. Verifica-se que, malgrado as reais tentativas de mutação de concepções sociais a partir da 
reformulação de ideais jurídicos, a implementação da nova política inspirada no paradigma da proteção integral ainda acontece, guardando indesejados resquícios do antigo sistema de caráter menorista, em que a adolescente ainda é objeto de tutela estatal, marcada por traços notadamente morais, e isenta de status de sujeito.

A ausência de estudos que deem voz a essas inúmeras meninas, que vivem diferentes opressões e discriminações (meninas negras, pobres, lésbicas, indígenas, trans, etc.), torna urgente a necessidade de repensar o controle do delito/infração dentro da nova realidade da fragmentação pós-moderna. A revelação feminista de que a violência cometida contra as mulheres e meninas está assentada nas relações hierárquicas de gênero, raça, classe e heteronormação mostra não ser mais possível sustentar uma perspectiva que não seja inclusiva do gênero, raça/etnia, sexualidade, idade e outros marcadores. Foi nesse sentido que caminhou a presente pesquisa, ao se preocupar em denunciar as problemáticas existentes no âmbito socioeducativo quando o corpo a ser domesticado é o da adolescente, corpo este carregado de características próprias atinentes à sua condição peculiar de pessoa em desenvolvimento, transpassado por múltiplas dimensões, as quais, ao gerarem vulnerabilidades específicas, ocasionam, por consequência, violências ainda mais ultrajantes.

Pois bem. Num modelo de liberdade próprio do Estado democrático de direito, maneiras de subordinação feminina, expressas em sentenças como as expostas, não podem mais ser toleradas.

\section{REFERÊNCIAS}

ABBAGNANO, Nicola. Dicionário de Filosofia. 2 ed. São Paulo: Mestre Jou, 1962.

ANCHIETA, Vânia Cristine Cavalcante; GALINKIN, Ana Lúcia. Policiais Civis: representando a violência. Psicologia \& Sociedade, n. 17 (1), p. 29-37, jan/abr, 2005.

ANDRADE, Vera Regina Pereira de. A soberania patriarcal: o sistema de justiça criminal no tratamento da violência sexual contra a mulher. Revista Seqüência, n. 50, p. 71-102, Florianópolis, jul. 2005.

AZEVEDO, Rodrigo Ghiringhelli de. A Força do Direito e a Violência das Formas Jurídicas Contribuição à Análise Sociocriminológica do Direito. In: GAUER, Ruth Maria Chittó (Org.) Criminologia e Sistemas Penais Contemporâneos II. Porto Alegre: EDIPUCRS, 2010.

BARATTA, Alessandro. Criminologia crítica e crítica do direito penal. 2. ed. Rio de Janeiro: Freitas Bastos, 1999.

. O paradigma do gênero. Da questão criminal à questão humana. In: CAMPOS, Carmen Hein de (Org.). Criminologia e feminismo. Porto Alegre: Sulina, 1999b, p. 19-80.

BARDIN, Laurence. Análise de conteúdo. Lisboa: Edições 70, 1977. 
BAUER, Martin W.; GASKELL, George. Pesquisa qualitativa com texto, imagem e som. Rio de Janeiro: Vozes, 2002.

BECKER, Howard S. Falando da sociedade. Ensaios sobre as diferentes maneiras de representar o social. Rio de Janeiro: Zahar, 2009.

. Métodos de pesquisa em ciências sociais. São Paulo: Hucitec, 1993.

BOURDIEU, Pierre. Poder Simbólico. 13. ed. Rio de Janeiro: Bertrand Brasil, 2010.

BREITMAN, Mirian Rodrigues. Criminalidade feminina: outra versão dos papéis da mulher. Sociologias, Porto Alegre, ano I, n. 1, p. 200.

BUTLER, Judith. Gender trouble: feminism and de subversion of identity. London: Routledge, 1990.

COIMBRA, Raquel Lordello. A utilidade social do direito da criança e do adolescente. Direito $e$ Paz, ano 7, n. 12, p. 121-137, Centro Universitário Salesiano de São Paulo, 2005.

DERRIDA, Jacques. Força de lei: o fundamento místico da autoridade. 2. ed. São Paulo: Martins Fontes, 2010.

DOLINGER, Jacob. A criança no Direito Internacional. Rio de Janeiro: Renovar, 2003.

FÓRUM BRASILEIRO DE SEGURANÇA PÚBLICA. Anuário Brasileiro de Segurança Pública 2014. São Paulo, ano 8, 2014.

FOUCAULT, Michel. A ordem do discurso. Aula Inaugural no Collège de France, pronunciada em 2 de dezembro de 1970. 20. ed. São Paulo: Edições Loyola, 2010.

FREIRE, Christiane Russomano; AZEVEDO, Rodrigo Ghiringhelli de. As representações sociais sobre o castigo - magistrados, policiais e administradores penitenciários no RS. Anpocs, 2013.

GARCÍA MÉNDEZ, Emilio. Infância e cidadania na América Latina. São Paulo: Hucitec, 1998.

GARLAND, David. As Contradições da "Sociedade Punitiva”. Revista de Sociologia e Política, n. 13, 1999, p. 59-80.

HARAWAY, Donna. “Gênero” para um dicionário marxista: a política sexual de uma palavra. Cadernos Pagu, n. 22, 2004, p. 201-246.

HORMAZÁBAL MALARÉE, Hernán. El Derecho Penal subjetivo y sus limitaciones. Alter. Revista Internacional de Taría Fiolofia y Sociología del Derecho, n. 1, Nueva Época, p. 130-144, enero, 2006.

KERGOAT, Danièle. Dinâmica e consubstancialidade das relações sociais. Novos Estudos CEBRAP, São Paulo, n. 86, p. 93-103, mar. 2010. Disponível em: <http://goo.gl/sPbz8f >. Acesso em: 10 fev. 2016. 
LIMA, Maria Emília A. T. Análise de discurso e/ou conteúdo. Psicologia em revista, v. 9, n. 13, Belo Horizonte, p. 76-88, jun., 2003.

MELLO, Marília Montenegro Pessoa de. Da honestidade à igualdade: desconstruindo a classificação das mulheres na legislação penal brasileira. In: SILVA, Ivan Luiz da; CARDOZO, Teodomiro Noronha; EL HIRECHE, Gamil Foppel. Ciências Criminais no século XXI - Estudos em homenagem aos 180 anos da Faculdade de Direito do Recife. Recife: Editora Universitária UFPE, 2007, p. 439-483.

MUTTI, Regina; CAREGNATO, Rita Catalena. Pesquisa qualitativa: análise de discurso versus análise de conteúdo. Texto Contexto, n. 15, v. 4, out.dez, p. 679-684, Florianteúdo.03.m=is

NASCIMENTO-SCHULZE, Clélia Maria; CAMARGO, Brígido Vizeu. Psicologia social. Representações sociais e métodos. Temas em Psicologia da SBP, v. 8, n. 3, p. 287-299, 2002.

OBSERVATÓRIO NACIONAL DOS DIREITOS DA CRIANÇA E DO ADOLESCENTE (ONDCA). SIPIA-SINASE. 2014. Disponível em: <http://www.sipia.gov.br> Acesso em: 10 de fev. de 2016.

OLIVEIRA, Suely de. Nem homem gosta de bater, nem mulher de apanhar: fortalecendo a rede de proteção. In: CASTILLO, Martín Márcia; OLIVEIRA, Suely de (Org.). Marcadas a ferro: violência contra a mulher - uma visão multidisciplinar. Brasília: Secretaria Especial de Políticas para as mulheres, 2005.

PISCITELLI, Adriana. Recriando a (categoria) mulher? In: ALGRANTI, L. (Org.). A prática feminista e o conceito de gênero. Textos Didáticos, n. 48. Campinas: IFCH/Unicamp, 2002, p. 7-42.

PORTO, Maria Stella Grossi. Crenças, valores e representações sociais da violência. Sociologias, n. 16, p. 250-273, 2006.

REGIS, Jolivet. Curso de Filosofia. 19. ed. Rio de Janeiro: Agir, 1995.

ROCHA, Dércio; DEUSDARÁ, Bruno. Análise de conteúdo e análise do discurso: aproximações e afastamentos na (re)construção de uma trajetória. Alea, v. 7, n. 2, p. 7-12, 2005.

RUBIN, Gayle. O Tráfico de Mulheres: notas sobre a “economia política” do sexo. Recife: SOS Corpo, 1993.

SÁ, Celso Pereira de. Núcleo central das representações sociais. Petrópolis: Vozes, 2002.

SAFFIOTI, Heleieth I. B. Gênero e Patriarcado. In: CASTILLO-MARTÍN, Márcia; OLIVEIRA, Sueli de. Marcadas a Ferro. Violência contra a Mulher. Uma Visão Multidisciplinar. Brasília: Secretaria Especial de Políticas para as Mulheres, 2005, p. 35-76.

VALA, Jorge. Sobre as representações sociais - para uma epistemologia do senso comum. Cadernos de Ciências Sociais, n. 4, abril, Porto, 1986. 
; CASTRO, Paula. Pensamento social e representações sociais. In: VALA, Jorge; MONTEIRO, Maria Benedicta (Coord.) Psicologia social. 9. ed. Lisboa: Fundação Caloutes Gulbenkian, 2013.

ZAFFARONI, Eugenio Raúl; PIERANGELI, José Henrique. Manual de direito penal brasileiro Parte geral. 2. ed. São Paulo: Editora Revista dos Tribunais, 1999.

\title{
SENTENCES OF YOUTH DETENTION AND GENDER - THE LOOK OF THE MAGISTRATES IN PERNAMBUCO ON FEMALE ADOLESCENTS IN CRIME
}

\begin{abstract}
Considering the current high rates of detention of female adolescents - under the theoretical view of the feminist critic criminology, subsidized by the labeling approach - the following question is justified and necessary: Do the perceptions of magistrates regarding gender - such as "the role of woman" and the expectation about this "role", fruit of the patriarchal structure of the society influence the judicial sentencing decision? The research aimed to investigate the existence, by the magistrates, of gender-stereotype elements. To this end it was used the deductive methods of analysis of bibliography that covers gender issues within social relations as well as the analysis of the content of twenty-eight sentences given by magistrates from 2010 to 2012 in the state of Pernambuco (Northeast Brazil). The arguments of the magistrates were regarded as patriarchal conceptions, classified into categories which endorse a stereotypical vision of gender, imbued with a camouflaged desire of control over females, so that the judicial activity works as a public mechanism of punishment to those girls who run away from the informal control, reinforcing the patriarchal control by criminalizing them in specific situations, notably when they transcend the ethos reserved for the female role.
\end{abstract}

\section{KEYWORDS}

Female adolescents. Judicial decisions. Stereotypes. Gender. 